Article

\title{
Varying Ignition Quality of a Fuel for a HCCI Engine Using a Photochemically-Controlled Additive: The Development of a 'Smart' Fuel
}

\author{
David Emberson ${ }^{1, *(\mathbb{C}}$, Judit Sandquist $\left.{ }^{2} \mathbb{(}\right)$, Terese Lovås ${ }^{1}$, Alessandro Schönborn ${ }^{3}$ and Inge Saanum ${ }^{2}$ \\ 1 Department of Energy and Process Engineering, Norwegian University of Science and Technology, \\ 7491 Trondheim, Norway; terese.lovas@ntnu.no \\ 2 SINTEF Energy AS, 7034 Trondheim, Norway; judit.sandquist@sintef.no (J.S.); inge.saanum@sintef.no (I.S.) \\ 3 Maritime Energy Management (MEM), World Maritime University, Fiskehamnsgatan 1, \\ 21118 Malmö, Sweden; as@wmu.se \\ * Correspondence: david.r.emberson@ntnu.no
}

Citation: Emberson, D.; Sandquist, J.; Løvås, T.; Schönborn, A.; Saanum, I. Varying Ignition Quality of a Fuel for a HCCI Engine Using a

Photochemically-Controlled Additive: The Development of a 'Smart' Fuel. Energies 2021, 14, 1470. https:// doi.org/10.3390/en14051470

Academic Editor: Michele Battistoni

Received: 18 January 2021

Accepted: 22 February 2021

Published: 8 March 2021

Publisher's Note: MDPI stays neutral with regard to jurisdictional claims in published maps and institutional affiliations.

Copyright: (c) 2021 by the authors. Licensee MDPI, Basel, Switzerland. This article is an open access article distributed under the terms and conditions of the Creative Commons Attribution (CC BY) license (https:/ / creativecommons.org/licenses/by/ $4.0 /)$.

\begin{abstract}
This study examines the possibility to provide control over ignition timing in a homogeneous charge compression ignition engine (HCCI) using a fuel additive whose molecular structure can be adapted upon exposure to UV light. The UV adapted molecule has a greater influence on retarding ignition than the original molecule, hence the ignition time can be modulated upon expose to UV light. The new fuel is referred to as a 'smart fuel'. The fuel additive is in the form of 1,3-cyclohexadiene (CHD), upon UV exposure it undergoes electro-cyclic ring opening to form 1,3,5hexatriene (HT). Various solutions of iso-octane, n-heptane and CHD have been irradiated by UV light for different amounts of time. CHD to HT conversion was examined using gas chromatography coupled with mass spectrometry. A primary reference fuel (PRF) mixture of $90 \%$ iso-octane and $10 \%$ n-heptane was used as a baseline in an optically accessible combustion chamber in a large bore, single cylinder compression ignition engine. The engine was operated in HCCI mode, using early injection to provide homogeneous mixture and utilized heated and compressed air intake. Following this a PRF with 5\% CHD was used in the engine. A PRF with 5\% CHD was then irradiated with UV light for $240 \mathrm{~min}$, resulting in a PRF mixture containing $1.72 \% \mathrm{HT}$, this was then used in the engine. The HT containing PRF had a much later start of combustion compared with the CHD containing PRF, which in turn had a later start of combustion compared with the PRF baseline. This study has successfully validated the concept of using a photo-chemical 'smart' fuel to significantly change the ignition quality of a fuel in HCCI mode combustion and demonstrated the concept of on-board 'smart fuel' applications for ICE.
\end{abstract}

Keywords: HCCI; ignition; photo-chemical; fuel additive; 1,3-cyclohexadiene; 1,3,5-hexatriene

\section{Introduction}

In an effort to reduce regulated emissions and increase thermal efficiency of internal combustion engines (ICE), new equipment, fuels and combustion strategies are under investigation. To reduce NOx it is desirable to reduce peak flame temperatures, achievable by having an overall fuel lean mixture, avoiding any regions of stoichiometric mixture formation. To reduce soot, and therefore a portion of exhaust particulate matter (PM), it is desirable to have a homogeneous mixture, with no fuel rich regions.

In traditional compression ignition (CI) engines, there will always be some regions of high peak flame temperature and fuel rich regions due to fuel-air mixing in the cylinder; however, thermal efficiency is high due to the higher compression ratios used. In traditional spark ignition (SI) engines, there will be an overall homogeneous, stoichiometric fuel-air mixture, so soot is largely avoided. There will be regions of high flame temperature as the flame front progresses through the stoichiometric mixture resulting in high levels of 
NOx production. An SI engine will produce more NOx than a CI engine, both in terms of $\mathrm{g} / \mathrm{kWh}$ and ppm under comparable load and speed conditions; however, stoichiometric operation in SI engines allows the use of a three way catalyst. These are extremely effective at reducing NOx, therefore exhaust out emissions after the catalyst are much lower for an $\mathrm{SI}$ engine than a comparable $\mathrm{CI}$ engine [1]. The requirement to maintain a stoichiometric mixture in traditional (port injected) SI engines means that as fuel quantity is varied (load), so too is the air quantity, leading to the requirement to throttle the air flow into the engine, resulting in pumping losses, reducing cycle efficiency [1]. Furthermore, the knock limit of the fuel used in an SI engine means compression ratio must be reduced, leading to further reduction in cycle efficiency. CI engines operate un-throttled, as load is varied by changing fuel quantity only (non-stoichiometric) vastly reducing pumping loses, combined with the higher compression ratios used results in a higher cycle efficiency.

In a bid to reduce flame temperatures; use a lean mixture; utilize a homogeneous mixture; avoid throttling and; maintain a high compression ratio, strategies such as homogeneous charge compression ignition (HCCI), premixed charge compression ignition (PCCI) and reactivity controlled compression ignition (RCCI) have been examined. These strategies make use of homogeneous or near homogeneous fuel-air mixtures in the engine cylinder during the compression stroke. The mixture is always lean (equivalence ration $<1$ ) and air intake throttling is not required. Combustion is initiated by compression, with no spark and no flame front to consider. Ignition ideally occurs in a great number of locations in the combustion chamber at nearly the same time [2-4]. It has been observed that these combustion strategies can simultaneously reduce NOx and soot emissions whilst maintaining high cycle efficiencies [1].

One of the main challenges of HCCI, PCCI or RCCI mode combustion is controlling the ignition to occur at the desired time in the cycle, usually at or near top-dead-centre (TDC) [5]. Ignition timing is entirely dependent on the chemical kinetics of the reaction (combustion) occurring in the fuel-air mixture $[5,6]$. The chemical kinetics are primarily dependent on the mixture chemistry (chemical composition of the fuel, the stoichiometry, the fuel-air ratio) and mixture thermodynamics (temperature and pressure), that define the system.

Chemistry may be adjusted by changing to a different fuel, using fuel additives, changing fuel-air ratios, introducing exhaust gas re-circulation (EGR) or by chemically changing the fuel entering the combustion chamber. Thermodynamic, i.e., temperature and pressure adjustment requires physical changes in engine operation, such as variations in effective compression ratio, intake air heating, supercharging/turbocharging, varying valve timing as well as EGR. EGR will have both a chemical and thermodynamic effect due to the composition of the gases (combustion products) and the high temperature and change in specific heat ratio of the cylinder gases. Physical changes in engine operation are effective in controlling ignition, but some of the conditions achieved in lab may be difficult to achieve in real world systems or result in efficiency losses, i.e., from heating intake air or supercharging.

RCCI mode combustion aims to solve the ignition control problem of HCCI by utilizing fuels or additives that can be used in different quantities (concentrations) to change the reactivity of the fuel in the fuel-air mixture. Two fuels of varying ignition quality may be used, where by the ignition quality of the mixture can be adjusted to achieve ignition at the desired time [7]. The gross indicated thermal efficiency of this type of combustion engine has been reported to reach $55-60 \%$, a $20-33 \%$ improvement compared to conventional CI engines [1,8]. RCCI implemented using two separate injection systems can use two fuels to prepare a stratified mixture of fuel and air having high and low reactivity within the cylinder $[7,8]$. The electronic control unit of the engine may control blending of the fuels in ideal proportions, to adjust the point of ignition to the point of maximum compression $[5,7,9]$. Due to its high efficiency, this is one of the most promising ways of making HCCI practical, but the use of two fuels is problematic in practice, since it requires two separate fuel tanks on board of every vehicle. A single fuel tank may be 
used if there is some way to alter ignition character of the fuel on board. An example of this methodology is described in the work [10] where a reforming process is applied to a single fuel to generate a hydrogen rich gas which is used to effectively decrease the cetane number of the mixture (reduce the reactivity). Another method suggested is to provide a cetane number improving additive such as 2-ethylhexyl nitrate (2-EHN), which may be added to a single-fuel supply in differing amounts in order to vary ignition quality $[7,11]$. While this is in principle possible, experiments conducted using 2-EHN and petrol have been shown to require a fraction of about 3.5\% 2-EHN in the fuel [7]. In order to only have to refuel the 2-EHN supply in intervals of a mere 20 tanks, a $3.5 \mathrm{~L}$ tank of 2-EHN would be necessary. Considering that 2-EHN and other cetane improving additives are all explosive (even in the total absence of any oxygen) carrying 3.5 L of 2-EHN on board a vehicle would be a dangerous technical solution. It is desirable to use an additive that may be used in small quantities to adjust the ignition, thus reducing the requirement to refill any auxiliary tank regularly; further, if the effectiveness of this additive could be changed on demand, a so called 'smart fuel' can be developed, resulting in a further reduction of additives usage and a high degree of control over ignition timing.

Yao et al. [12] proposed that methanol could be dehydrated to dimethyl-ether, to provide a second fuel of differing ignition quality using a single fuel supply of methanol. It has been demonstrated that ozone can be used to partially alter the molecular structure of the fuel into peroxides prior to combustion, as a means of controlling ignition timing [13]. Photo-chemical reactions have also been shown to be effective in reducing ignition delays of reactant mixtures; this has predominantly been achieved by decomposing molecular oxygen into atomic oxygen [14,15]. In previous work by one of the authors, RCCI mode combustion of iso-propanol that had been partially reacted into propane peroxide during a photo-chemical reaction with air (prior to combustion) was simulated numerically [16].

This study examines a similar photo-chemically active fuel additive which is applied to a HCCI engine to achieve an element of control over the ignition timing. The additive is in the form of 1,3-cyclohexadiene and has been investigated as an additive applied to a primary reference fuel blend (PRF) of iso-octane and n-heptane. Photo-chemical, electro-cyclic ring-opening of 1,3-cyclohexadiene (CHD from here) leads to the formation of 1,3,5-hexatriene (HT from here) (Figure 1).

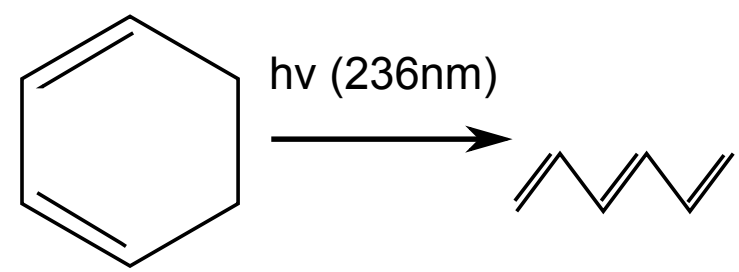

Figure 1. Change in molecular structure of 1,3-cyclohexadiene dimerisation to 1,3,5-hexatriene by electrocyclic ring-opening.

Minaard and Havinga [17] have shown that this photo-chemical reaction can be carried-out in the liquid phase at high dilution, using a mixture of $1 \%$ CHD in $99 \% \mathrm{n}$ pentane, leading to an $80 \%$ conversion of CHD to HT after less than 220 min exposure to UV radiation. The light energy required for the photo-chemical reaction, represents approximately $0.3 \%$ of the fuel energy, thus being significantly smaller than the energy savings of around $20 \%$ promised by using RCCI [1]. Both CHD and HT have been examined in a preliminary numerical study (Section 1) and will be shown in this study to effectively alter the ignition timing when blended with an iso-octane and n-heptane PRF.

The work presented here is limited in scope, being very much a "proof of concept", with the study established to validate the photo-chemical ring opening conversion of CHD to HT using UV light and the premise of using this CHD to HT as a an ignition changing additive. The CHD to HT conversion process was conducted using two photo-reactors with subsequent HT product yield tested for conversion efficiency. A PRF blend, a PRF 
containing CHD and a PRF containing CHD converted to HT ('smart fuel') was then used in an optical HCCI combustion chamber to examine the impact on ignition, combustion pressure and heat release rate.

\section{Numerical Simultation}

The chemical kinetic simulations in Figure 2 were conducted in the same manner as the previous Cantera simulations [16] and show that as 1,3-CHD is converted to 1,3,5-HT its reactivity is significantly reduced, causing the mixture to ignite progressively later in the engine cycle, until its ignition is eventually suppressed. Figure 2 predicts that ignition timing control in an HCCI engine using a 'smart'- photo-chemical fuel additive based on electro-cyclic ring-opening reactions is possible.
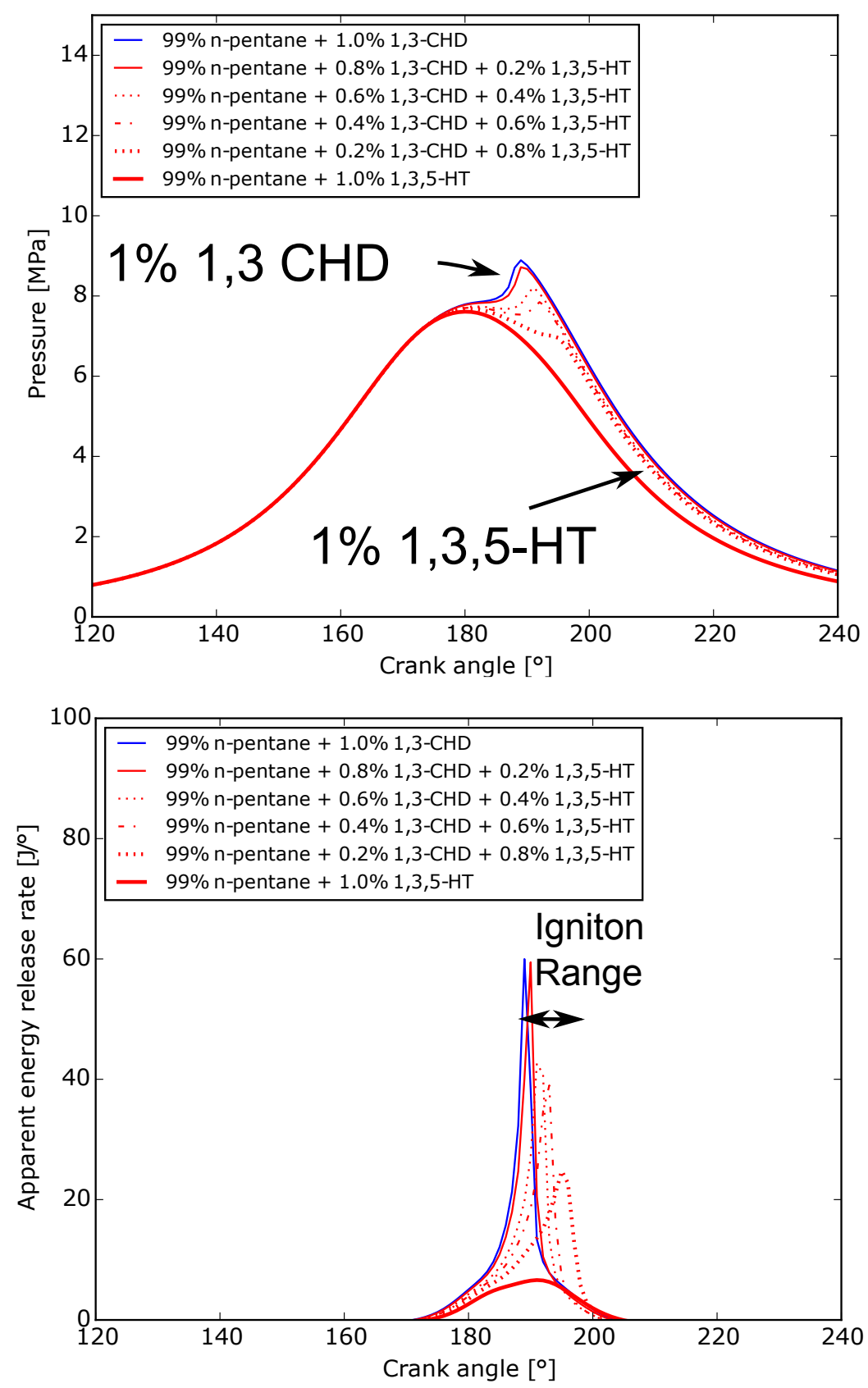

Figure 2. Chemical kinetic engine simulation of a 1\% 1,3-cyclohexadiene (1,3-CHD) in 99\% n-pentane converted in various fractions to $1,3,5$-hexatriene $(1,3,5-\mathrm{HT})$. The cylinder pressure (upper graph) and apparent heat release rate (lower graph) show that a concentration of $1 \%$ is effective in controlling ignition photo-chemically in the engine. 


\section{Experimental Methods}

\subsection{Fuel Production and Analysis}

Two laboratory scale reactors were employed in this study. A smaller setup with a Pen-Ray lamp, using smaller volumes $(20 \mathrm{~mL})$ for screening purposes; and a larger, immersed well type reactor used to produce larger volumes $(150 \mathrm{~mL})$, and a sufficient volume to be used in the engine $(400 \mathrm{~mL})$.

\subsubsection{Pen-Ray Lamp Experiments}

Solutions containing, iso-octane, (Emsure, Merck, Germany, purity 99.5\%) or nheptane (Emsure, Merck, Germany, purity 99\%) with 5 vol\% concentration of the cyclohexadiene (Alfa Aesar, purity $96 \%$ stabilized with $0.1 \%$ BHT ) were irradiated for $120 \mathrm{~min}$ with a $254 \mathrm{~nm}$ UV light. Total solution volume for each case solution tested was $20 \mathrm{~mL}$.

The solutions were placed in a round bottomed flask, sealed and placed into a water bath (see Figure 3, image on left.) Both the irradiated solutions and water bath were stirred with magnetic stirrer at $250 \mathrm{rpm}$. The UV lamp (UVP Pen-Ray ${ }^{\circledR}$ mercury lamp, model 11SC-2.12, Upland, CA, USA) was inserted through the cap.

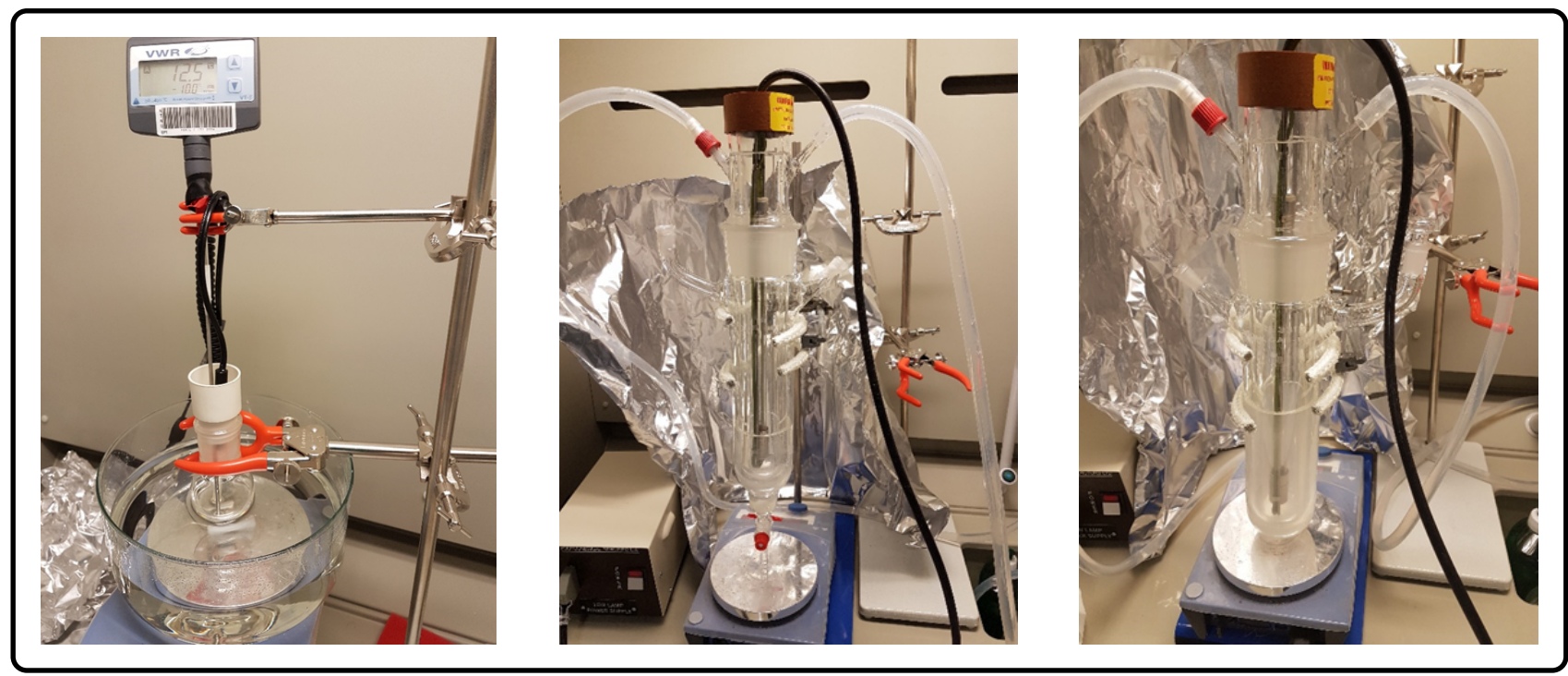

Figure 3. Reactors used. (Left)—roundbottom flask with Pen-Ray lamp inserted, in water bath. (Center)—immersion well reactor. (Right) - the configuration of the reactor resulted in limited space available for the stirrer magnets, therefore the reactor flask was modified with the bottom tap of the reactor removed.

\subsubsection{Immersion Well Reactor Experiments}

An immersion well reactor from Photochemical Reactors Ltd. utilizing a $16 \mathrm{~W}$ low pressure mercury lamp was used in the larger scale experiments. The lamp is contained in a double-walled immersion well made of quartz, with water cooling between the lamp and reactant solution (see Figure 3, center and right images). The low pressure lamps emit over $90 \%$ of their radiation at $254 \mathrm{~nm}$. In this set up the solution volume was increased to $150 \mathrm{~mL}$. The irradiation time was varied between 60 and $180 \mathrm{~min}$.

One experiment was performed to produce a fuel blend for the HCCI engine tests (ET from here). This required a larger volume to be produced than in the previous samples, which were used to examine the effect of scale, irradiation time, proof of concept and effectiveness of the reactor set-up. The ET sample was done with the immersion well reactor, using a $400 \mathrm{~mL}$ reactor glass. The ET solution produced was: $212.5 \mathrm{~g}$ iso-octane; $25 \mathrm{~g}$ n-heptane; and $12.5 \mathrm{~g} \mathrm{CHD}$, giving a component concentration on a mass basis of 85 , $10 \%$ and $5 \%$ respectively. Due to the density differences, the mixing ratio gives $4.1 \mathrm{v} / \mathrm{v} \%$. 
During fuel preparation, a white wax-like solid substance precipitated. The wax was mostly attached to the glass surface. The wax was not separated before irradiation, but the irradiated fuel was decanted prior to the HT analysis as well as the engine tests. It is assumed that the wax formation was due to the stabilizing additives in the CHD and was not affecting the reaction or the engine tests. To confirm this assumption, further analysis is needed. The ET mixture was irradiated for $240 \mathrm{~min}$ to compensate for the larger reactor volume and ensure the HT target in the final solution was reached. An overview of the solutions used during experimentation is given in Table 1.

Table 1. Overview of the fuel solutions produced.

\begin{tabular}{llll}
\hline $\begin{array}{l}\text { Experiment } \\
\text { (Solution) }\end{array}$ & $\begin{array}{l}\text { Solvent } \\
\boldsymbol{v} / \boldsymbol{v} \%\end{array}$ & $\begin{array}{l}\text { CHD } \\
\boldsymbol{v} / \boldsymbol{v} \%\end{array}$ & $\begin{array}{l}\text { Irradiation } \\
\text { Time (min) }\end{array}$ \\
\hline ISO0 & 95 Iso & 5 & 0 \\
ISO60 & 95 Iso & 5 & 60 \\
ISO120 & 95 Iso & 5 & 120 \\
ISO180 & 95 Iso & 5 & 180 \\
HEP0 & $95 \mathrm{Hep}$ & 5 & 0 \\
HEP60 & $95 \mathrm{Hep}$ & 5 & 60 \\
HEP120 & $95 \mathrm{Hep}$ & 5 & 120 \\
HEP180 & $95 \mathrm{Hep}$ & 5 & 180 \\
\hline ET & 85 wt\% Iso + & $5 \mathrm{wt} \%$ & 240 \\
(engine tests) & $10 \mathrm{wt} \%$ Hep & & \\
\hline
\end{tabular}

\subsubsection{Fuel Analysis}

Gas chromatographic coupled with mass spectrometric analyses (GCMS) was performed with an Agilent 7890 A gas chromatograph equipped with a 5975 C MDS mass spectrometer (Agilent Inc., Palo Alto, CA, USA) at SINTEF Materials and Chemistry laboratories. The mass spectrometer was used in the EI (electron impact) mode. The analyses were separated on a $30 \mathrm{~m}$ Agilent HP-5 column, the injector temperature was $150{ }^{\circ} \mathrm{C}$ and the injection volume was $0.5 \mu \mathrm{L}$. The column temperature was ramped from $40{ }^{\circ} \mathrm{C}$ to $125^{\circ} \mathrm{C}$. The mass spectrometer was operated in the scan mode over a $\mathrm{m} / z$ (mass-to-charge ratio) range from 30 to 800 , ion source temperature was $230{ }^{\circ} \mathrm{C}$ and quadruple temperature was $150^{\circ} \mathrm{C}$. Based on the results from scan analyses, an SIM (selected ion monitoring) method was made for hexatriene $(\mathrm{m} / \mathrm{z} 77$ and 79$)$. Mass spectrometric scan data was processed by NIST/AMDIS (National Institute for Standards and Technology, Boulder, CO, USA). Hexatriene was quantitated by calibration with reference compound (cis/trans 1,3,5-hexatriene, A1-00578, from ABCL, A1 BioChem Labs, Wilmington, NC, USA, purity >95\%).

Samples were prepared by dilution I-dichloromethane (up to 1: 10,000), which was found to be the best dilution solvent. Cetane number tests were performed by Intertek (Rotterdam, the Netherlands) following the ASTM D6890 method.

\subsection{HCCI Testing}

\subsubsection{Optically Accessible Compression Ignition Chamber}

The irradiated ET sample was tested in an optically accessible compression ignition chamber (OACIC) operated in HCCI mode. The chamber is located in the head of a single cylinder CI engine (Figure 4). The original engine was an indirect injection (IDI) type, with a Ricardo swirl chamber in the head. The original head has been replaced with a stainless steel block which houses a $50 \mathrm{~mm}$ diameter, $40 \mathrm{~mm}$ long cylindrical combustion chamber. This combustion chamber replaces the original IDI Ricardo swirl chamber and forms the OACIC. The head sits on top of a $1.8 \mathrm{~L}$ capacity, $130 \mathrm{~mm}$ bore, $137 \mathrm{~mm}$ stroke single cylinder engine (Lister CS, 12HP) The main cylinder volume of the engine and the combustion chamber volume in the head are connected via a throat, which is fitted with a removable insert, shown in detail in Figure 4. 


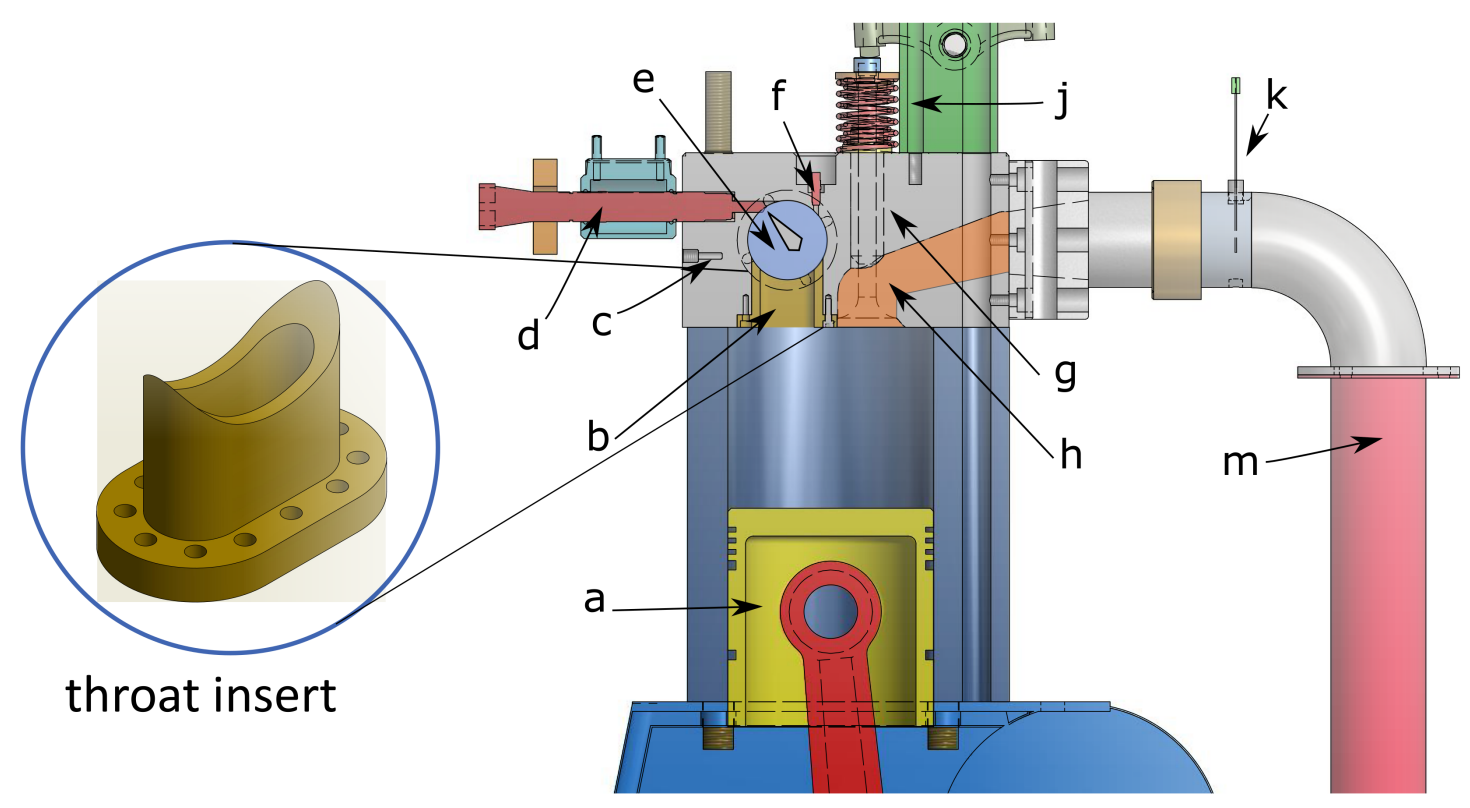

Figure 4. OACIC in place on top of single cylinder engine (a). Piston; (b). Connecting throat and insert; (c). Thermocouple; (d). Injector; (e). Optically accessible combustion region; (f). Pressure transducer; (g). Valves (h). Inlet and outlet; (j). Valve rocker arms; (k). Inlet pressure transducer and temperature thermocouple; (m). Inlet heater. Throat insert shown in detail.

The cylindrical combustion chamber is sealed at each end with fused silica windows, $63 \mathrm{~mm}$ diameter, $25 \mathrm{~mm}$ thick; thus optical access through the combustion region is achieved. The connecting throat features an insert which may be removed and replaced with a different shaped item or left out completely. This allows for a modification in the compression ratio as well as a modification of the flow field in the combustion chamber during the compression stroke of the engine. For all experiments the throat insert was removed, resulting in a geometric compression ratio of 14.35. This design provides optical access in an engine like environment whilst reducing some of the complexities of the flow field that would be associated with an optical engine. The design has also paid particular attention to the reduction of window fouling, allowing a large number of cycles to be repeated rapidly.

A Bosch, solenoid, common rail type injector is installed in the combustion chamber. The injector nozzle originally had 5 holes, with an included angle of $124^{\circ}$, hole diameter of $0.21 \mathrm{~mm}$ (nozzle code DSLA124P 1659). To avoid spray-spray interaction and spray window interaction and to allow fuel injection spray studies (not conducted in this work), the fuel injector is modified so only one hole was left open, with the remainder laser welded closed.

The injector is mounted in such a way as the spray emanates centrally across the combustion volume. The fuel injection system consists of a small $300 \mathrm{~mL}$ fuel tank which feeds an air operated pump (Sprague P4333). This is connected to a custom common rail system with a number of rails connected together to assist in smoothing out any pressure fluctuations. One of the rails is fitted with a pressure transducer, which defines the injection pressure $\left(\mathrm{P}_{i n j}\right)$ and is connected to the fuel injector. The fuel injector is fitted with a water cooled jacket around its main body to ensure consistent operation as the chamber heats up.

The chamber is installed with a pressure transducer (Kistler 6052). The temperature of the chamber, near the combustion volume is measured with a K-type thermocouple, placed on the center plane, with the measuring point approximately $17 \mathrm{~mm}$ from the combustion chamber wall. The inlet and exhaust is controlled by two valves, original to the engine, which are installed on one side of the head; these are controlled by a rocker gear, connected to a cam train in the crankcase by push-rods. Inlet pressure $\left(\mathrm{P}_{\text {inlet }}\right)$ and temperature $\left(\mathrm{T}_{\text {inlet }}\right)$ are measured at the manifold by an absolute pressure transducer (Kistler 4011A) and a K-type thermocouple, respectively. Inlet air is heated by an in-line electrical heater $(2 \mathrm{~kW})$. 
The air intake system is completed by: a Roots compressor, driven by an AC motor; a settling chamber after the compressor and; a large, $500 l$ air-box with an orifice plate installed. Air mass flow rate is determined from the pressure drop across the orifice plate. A combination of the large volume of the air-box, the Roots compressor and the setting chamber effectively damped out the large pressure pulses that would be experienced in the intake system due to the large displacement, single cylinder engine following a four-stroke cycle. For the experiments conducted in this study the exhaust gases were not analyzed or treated in any way, this will be the object of a later study. A schematic of the system is shown in Figure 5.

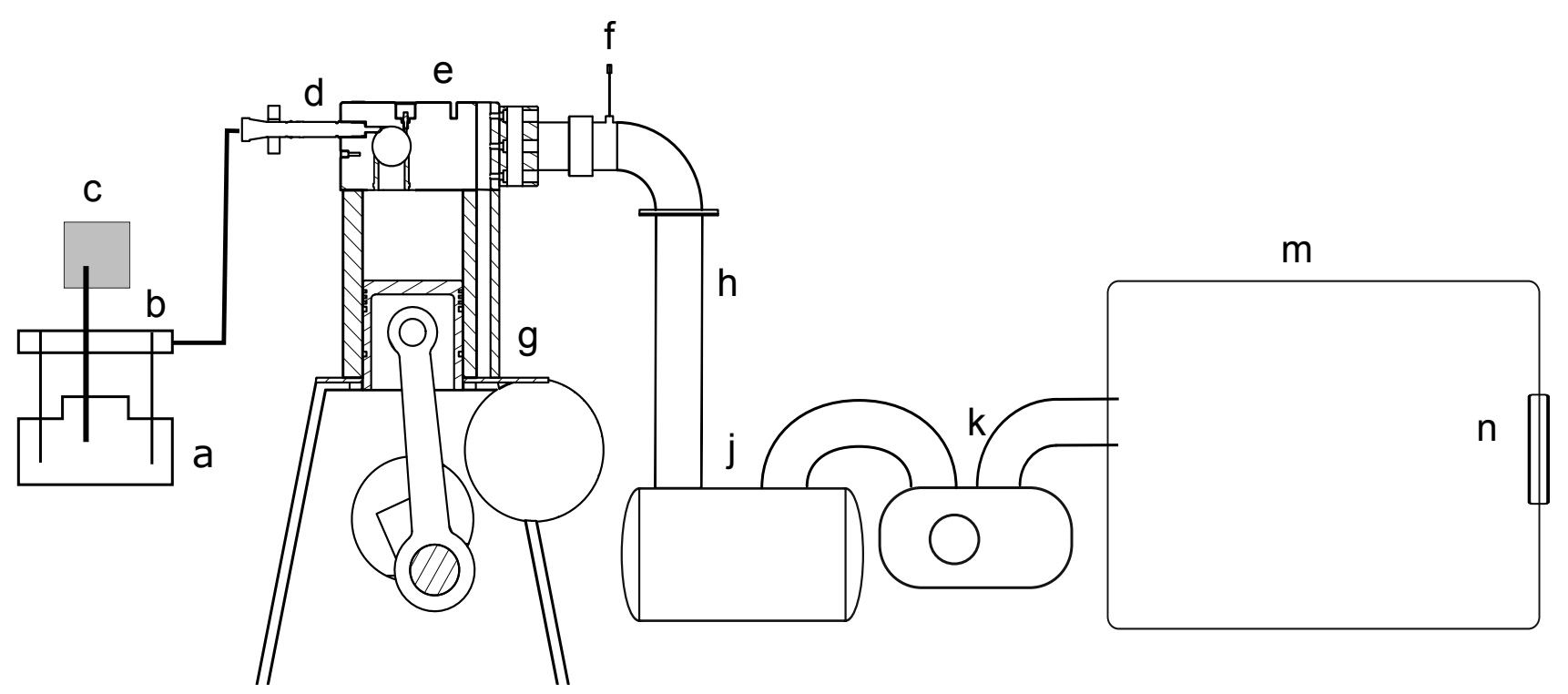

Figure 5. (a) High pressure pump; (b) Common rail; (c) Fuel tank; (d) Injector; (e) OACIC; (f) Inlet thermocouple and pressure transducer; (g) Engine; (h) Heater; (j) Settling tank; (k) Roots compressor; (m) Airbox; (n) Orifice plate.

The chamber operates similar to a rapid compression/expansion machine, with the engine crankshaft rotated by an AC motor (ABB LV160kW). The crankshaft is fitted with a shaft encoder with a resolution of 3200 signals per revolution. All control and data acquisition (DAQ) utilizes National Instruments Compact Rio and LabView, with timings pegged to the shaft encoder signal. For all tests conducted here the engine speed was $500 \mathrm{rpm}$; this engine speed has been chosen to minimize engine wear and stresses considering that the engine has been modified to operate with no oil.

Due to the current DAQ set-up, using a threshold applied to in-chamber pressure to identify a compression stroke over the four strokes of a cycle, the earliest injection achievable was 60 CAD BTDC. Tests have been conducted showing that at this injection timing, the mixture was quite homogeneous and can be seen in the work [18].

To determine the effect of the CHD to HT conversion on ignition, three fuels where tested. A PRF of $90 \%$ iso-octane and 10\% n-heptane (mass basis) was used as the baseline. An ET mixture of $85 \%$ iso-octane, $10 \%$ n-heptane and 5\% CHD was then tested. To ensure free flowing of the fuel and avoiding injector clogging by the wax like precipitate that had been observed (Section 2.1.2), the mixture was produced in a conical flask on a magnetic stirrer. On addition of the CHD, the wax-like precipitate was flung to the flask walls. The solution could then easily be decanted into a fresh conical flask containing no solid. No injector issues were experienced. Finally the irradiated, HT containing ET sample was tested in the engine. The three engine test fuels are refereed to as PRF, CHD and HT. For all cases $\mathrm{P}_{i n j}$ was 350 bar; $\mathrm{T}_{\text {inlet }} 90^{\circ} \mathrm{C}$ and $115^{\circ} \mathrm{C}$ and $\mathrm{P}_{\text {inlet }}$ was 1.36 bar. These two temperatures were used as they represent: the minimum inlet temperature at which stable, repeatable ignition of the PRF occurred with the ignition at the desired timing just before TDC (BTDC); also the minimum temperature when ignition of the HT fuel was 
observed during preliminary testing and; the maximum temperature achievable in the inlet at this time. Only one $P_{\text {inlet }}$ condition was tested due to limited volumes of fuel samples avaliable for testing; 1.36 bar is near the maximum $P_{\text {inlet }}$ achievable and was chosen partly to compensate for the removal of the connecting throat which reduced the geometric compression ratio. It was found to be $\mathrm{P}_{\text {inlet }}$ that resulted in repeatable PRF ignition near TDC and repeatable CHD and HT combustion at the two $\mathrm{T}_{\text {inlet }}$ conditions used, at higher $P_{\text {inlet }}$ it was found the PRF mixture tended to knock. An injection duration of $6 \mathrm{~ms}$, which results in an injection mass (measured using the PRF) of $27 \mathrm{mg}$ was used. This equates to two different equivalence ratios $(\phi)$, depending on $\mathrm{T}_{\text {inlet }} ; 0.18$ for $\mathrm{T}_{\text {inlet }}=90^{\circ} \mathrm{C}$ and 0.19 for $\mathrm{T}_{\text {inlet }}=115^{\circ} \mathrm{C}$, hence combustion is extremely lean. As the chamber is not continuously fired as a normal engine would be, there is no need for cooling. The cooling channels around the engine cylinder have been filled with oil and fitted with four cartridge type heaters. Cylinder temperature is kept constant at $90^{\circ} \mathrm{C}$, similar to the coolant temperature in an engine.

When the AC motor us started, the engine is motored (no fuel is injected). The chamber temperature starts to increase (due to compression of air in the cylinder), as measured by the thermocouple. Once this temperature had reached $130{ }^{\circ} \mathrm{C}$ the experiment could commence. The engine has been modified to operate with no oil so as to avoid soot production formed from the combustion of lucubrating oil. To avoid excessively long periods of motoring to raise temperature, removable heaters were made which install into the chamber. These were subsequently used to raise the temperature of the chamber to $130^{\circ} \mathrm{C}$. The temperature of $130^{\circ} \mathrm{C}$ was used as this was found to be the minimum temperature of the chamber that gave highly repeatable ignition and combustion characteristics. During experimentation, once the target temperature had been reached, injection was initiated, one injection per cycle, total of 10 times (10 injections per run). A skip fire strategy was employed, with fuel injection occurring every 10 cycles. This was done to minimize window fouling and also to remove residual gas trapped in the chamber. It was found that skip firing in this manner also reduced the temperature increase of the chamber so any effect that may have occurred due to the chamber heating was minimized. Combustion pressures, as well as various other pressures, temperatures and flow rates were all logged.

\subsubsection{Optical Set-Up}

A simplified optical set-up was used to capture flame images. A high speed, Photron SA5 camera was used with a Nikon $50 \mathrm{~mm} \mathrm{f} 1.2$ lens fitted with a Cannon close up lens. Frame rate was 20,000 fps with an exposure time of $49.75 \mu \mathrm{s}$. This exposure time was chosen as this was the minimum exposure applied which adequately captured the low signal from the flame. The large part of the signal captured by the camera is from chemiluminescence of intermediate species and was dominated by the blue portion of the spectrum. No intensification was applied so the early stages of ignition, dominated by UV emissions, will not have been detected. The camera was used to qualitatively access the homogeneity of the flame in the chamber and to identify the start of combustion from the inception of blue flames.

\section{Results and Discussions}

\subsection{Fuel Characterization}

\subsubsection{Pen-Ray Lamp Experiments}

The irradiation product of the 1,3-cyclohexadiene solutions contained both $(\mathrm{Z})$ and $(\mathrm{E})$ isomers of 1,3,5-hexatriene. The final product concentration was calculated by integrating the area below the curves from the GCMS for the two isomers and adding them together. The values were also converted to volume concentrations. The analysis results are presented in Table 2. 
Table 2. Analysis results of the Pen-Ray lamp experiments: hexatriene concentrations in the samples.

\begin{tabular}{lll}
\hline $\mathbf{1 , 3}, \mathbf{5}$-Hexatriene Concentration & $\boldsymbol{w} / \boldsymbol{v} \%$ & $\boldsymbol{v} / \boldsymbol{v} \%$ \\
\hline 1 min iso-octane & 0.014 & 0.02 \\
120 min iso-octane & 1.16 & 1.61 \\
120 min n-heptane & 1.11 & 1.54 \\
120 min iso-octane & & \\
analyzed 8 days later & 1.05 & 1.46 \\
\hline
\end{tabular}

The analysis results in Table 2 are averages of two or three different dilution results. After a minute, only $0.4 \%$ of the initial CHD was converted to HT product. The maximum HT yield was obtained after $120 \mathrm{~m}$ irradiation time in iso-octane. In that case, almost a third, $32 \%$ of the CHD was converted to HT. A slightly lower conversion, $31 \%$ was achieved when the solvent was changed to n-heptane. After 8 days storage (refrigerated) there was a reduction in the HT concentration of approximately $10 \%$. Hence, it is advised that the product is stored as short as possible, not more than 2-3 days prior to engine tests without reanalysis to avoid uncertainties due to degradation.

\subsubsection{Immersion Well Reactor Experiments}

In the immersion well reactor experiments the isomers of HT were altered. During Pen-Ray experiments the two HT isomers were formed in near equal quantities, but in the immersion well experiments, one of the isomers is produced in larger quantities. It is beyond the scope of this study and project to characterize the HT isomers and the reason behind the difference. It is however an interesting observation to explore in future studies. Table 3 and Figure 6 shows the obtained HT product yields in the immersion well reactor experiment as a function of irradiation time.

Table 3. Analysis results of the immersion well reactor experiments: hexatriene concentrations in the samples.

\begin{tabular}{lllll}
\hline Solution & $\boldsymbol{w / v \%}$ & $\mathbf{v / v a \%}$ & $\begin{array}{l}\text { Cetane } \\
\text { Number } \\
(\boldsymbol{b})\end{array}$ & $\begin{array}{l}\text { CHD } \\
\text { Conversion } \\
\mathbf{\%}\end{array}$ \\
\hline ISO0 & 0 & 0 & 14.9 & 0 \\
ISO60 & 0.55 & 0.76 & 14.0 & 15.2 \\
ISO120 & 0.75 & 1.04 & 15.5 & 20.8 \\
ISO180 & 1.24 & 1.72 & 14.6 & 34.4 \\
HEP0 & 0 & 0 & 49.3 & 0 \\
HEP60 & 0.6 & 0.83 & 49.7 & 16.7 \\
HEP120 & 1.1 & 1.53 & 50.5 & 30.6 \\
HEP180 & 1.42 & 1.97 & 50.7 & 39.5 \\
ET $(c)$ & 1.0 & 1.0 & n.a. & 23.4 \\
\hline
\end{tabular}

Density of the 1,3,5-hexatriene is $0.719 \mathrm{~g} / \mathrm{cm}^{3} b$ cetane number analyses are not reliable under 30, $c$ The CHD concentration in the engine test mixture was $5 w / w \%$ corresponding to $4.1 \mathrm{v} / \mathrm{v}$.

In the immersion well reaction experiments, somewhat lower HT product yields are obtained compared to the Pen-Ray experiments, with only $21 \%$ converted in the immersion well after two hours giving $1 \%$ product in the solution. The results can be explained by the lower total solution volume in the Pen-Ray experiments, while the total effect of the two lamps is similar. Another explanation might be that the cooling water which is found between the lamp and reactant solution in the immersion well setup absorbs some of the UV light. As Figure 6 shows the product yield was increased with increasing irradiation time. $34 \%$ of the initial CHD was converted to HT after three hours of irradiation time giving $1.72 \mathrm{vol} \% \mathrm{HT}$ in the solution. 


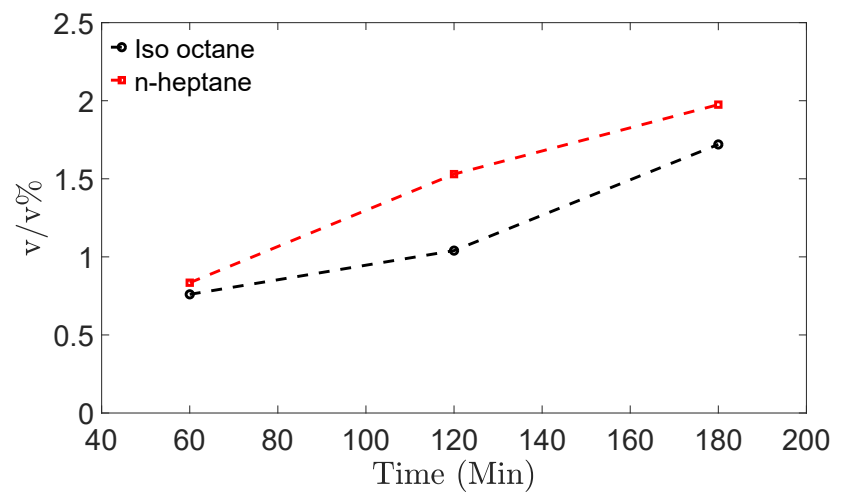

Figure 6. Hexatriene formation as a function of irradiation time.

\subsection{HCCI Testing}

The ET solution contained $5 w / w \%$ CHD. After irradiation, $23.4 \%$ of the CHD was converted to HT, resulting in an ET solution containing $1.17 \%$ HT. This mixture was then used in the OACIC. Combustion pressure has been collected and used to determine the start of combustion (SOC) and the heat release rate. SOC is defined as the time, in crank angle degrees (CAD), before TDC (BTDC) when ignition occurs. Optical measurements were performed to quantify the SOC timing and estimate homogeneity of mixture using the natural flame luminosity. For combustion pressures, the SOC was determined from the point on the HRR plots where the curve crosses 0 on the $y$-axis; for the flame intensity SOC, the SOC is determined from the Pixal mean plots where the curve first starts to rise from a zero value.

\subsubsection{Combustion Pressures and HRR}

Figure 7 shows the combustion pressure recorded in the OACIC fueled with PRF, CHD and HT along with motored pressure at $\mathrm{T}_{\text {inlet }} 90^{\circ} \mathrm{C}$. The plots show the mean pressure of eight combustion cycles as the first two combustion cycles are always discarded (10 injection conducted in total) to remove any fuel from the injector nozzle from previous motored cycles which would have been heated to high temperatures. For the PRF, the ignition occurred just prior to TDC. It is clear the addition of CHD to the PRF mixture retarded the $\mathrm{SOC}$ and has led to a reduction and retardation of the peak combustion pressure.

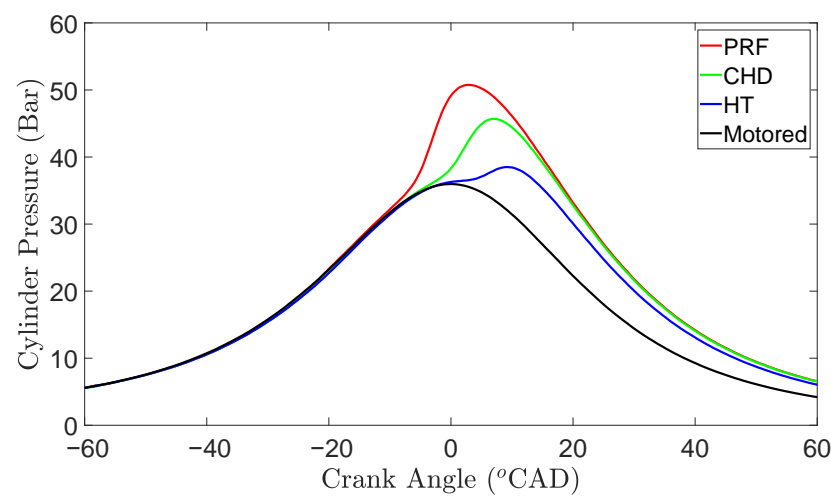

Figure 7. Combustion pressure for the three fuels and motored pressure with $\mathrm{T}_{\text {inlet }} 90^{\circ} \mathrm{C}$.

Upon irradiation and CHD to hexatriene conversion, the HT mixture has an even later SOC and the peak combustion pressure is much lower and occurs much later than the PRF or CHD mixtures.

Figure 8 shows the heat release rate (HRR) for the $\mathrm{T}_{\text {inlet }} 90^{\circ} \mathrm{C}$ condition with the three fuels. It is evident that not only had the effective 'cetane-number' of the mixture been reduced with the addition of $\mathrm{CHD}$ and $\mathrm{HT}$, but the total amount of energy released during the combustion process is drastically reduced. This suggests that combustion efficiency 
has been severely reduced with the CHD and HT cases. These results suggest that the addition of CHD and the subsequent HT concentrations could be done in much lower concentrations than used here to have a useful impact on retarding ignition.

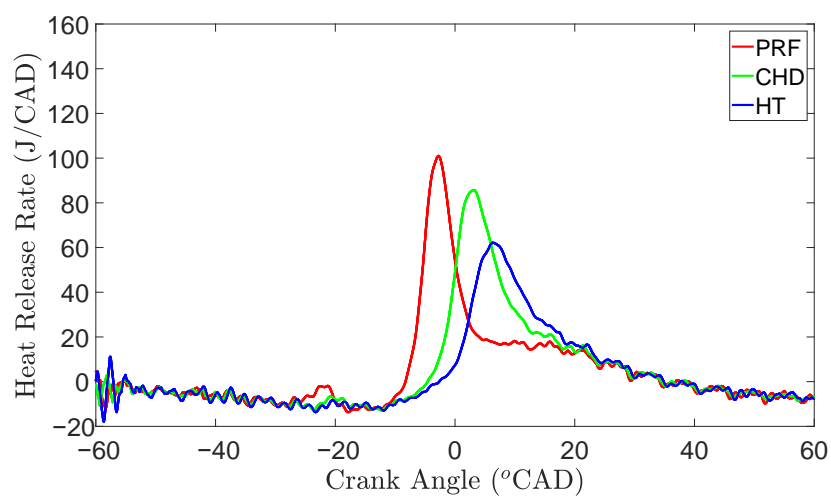

Figure 8. Heat release rate for the three fuels with $\mathrm{T}_{\text {inlet }} 90^{\circ} \mathrm{C}$.

Table 3 shows that in the iso-octane solutions, with increasing CHD to HT conversion (longer irradiation time) the cetane number varied slightly (as the cetane number is below 30 , the analysis is not reliable). In the pure heptane, where cetane number is in the 50 range, it is observed that increasing the time of irradiation (increasing CHD to HT) slightly increased the cetane number, therefore in a pure n-heptane ET solution, one would expect the SOC to advance. It is evident that the choice of the PRF components, i.e., containing iso-octane, is influential and that CHD to HT effect on ignition would maybe be less in an ET solution containing a larger percentage of heptane. The CHD to HT conversion may be useful in the adoption of more Diesel like fuels in HCCI/RCCI mode.

The same trend was observed in the tests conducted at $\mathrm{T}_{\text {inlet }} 115^{\circ} \mathrm{C}$ as shown in Figures 9 and 10. At this $\mathrm{T}_{\text {inlet }}$ the $\mathrm{CHD}$ mixture heat release rate and peak combustion pressure is much closer to that of the PRF, suggesting that the combustion efficiency of the $\mathrm{CHD}$ at the higher $\mathrm{T}_{\text {inlet }}$ is improved but the $\mathrm{SOC}$ has still been effectively retarded. The HT combustion has a higher peak combustion pressure at the higher $\mathrm{T}_{\text {inlet }}$ and a larger HRR.

The results collected here are in agreement with the numerical work presented in [19]. In that work the CHD and HT were numerically modeled using a mechanism in Canteria employing a simple single zone piston cylinder reactor model. The model used a mechanism developed for the combustion of cyclopentane and cyclohexane [20] with 1,3-CHD and 1,3,5-HT in various ratios in n-pentane (1\% CHD and HT, 99\% n-pentane).

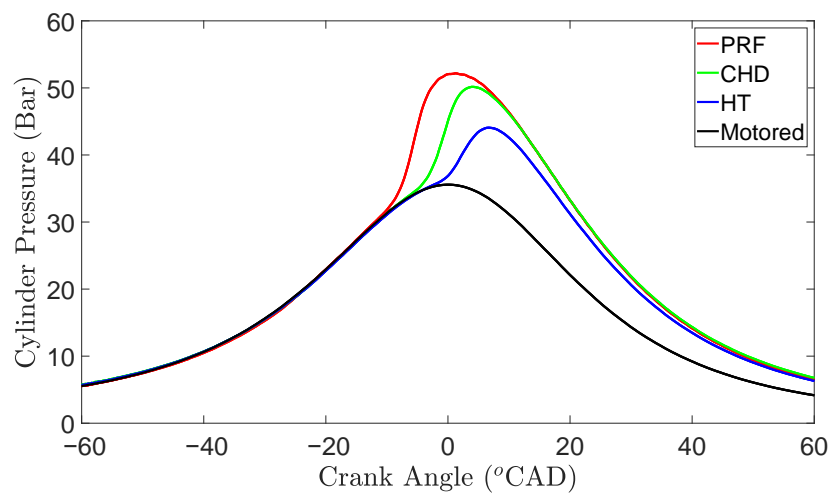

Figure 9. Combustion pressure for the three fuels and motored pressure with $\mathrm{T}_{\text {inlet }} 115^{\circ} \mathrm{C}$. 


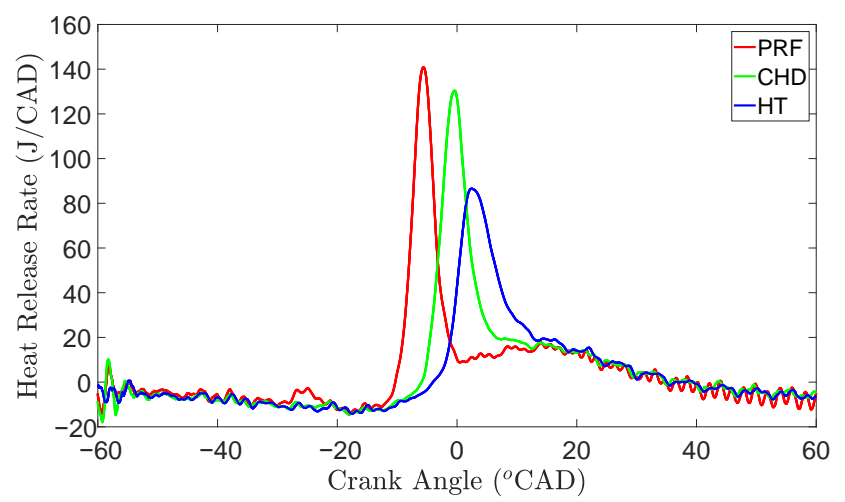

Figure 10. Heat release rate for the three fuels with $\mathrm{T}_{\text {inlet }} 115^{\circ} \mathrm{C}$.

Figure 11 shows the combustion pressure for the HT solution at $\mathrm{T}_{\text {inlet }} 90^{\circ} \mathrm{C}$ (blue) and $\mathrm{T}_{\text {inlet }} 115^{\circ} \mathrm{C}$ (red). The solid colored region shows the range of pressures collected for the 8 combustion cycles. The higher $\mathrm{T}_{\text {inlet }}$ resulted in more consistent combustion with the HT mixture with a smaller range of pressures evident. It was found during testing that at $\mathrm{T}_{\text {inlet }}$ below $90^{\circ} \mathrm{C}$ combustion of the $\mathrm{CHD}$ and the HT mixtures could be erratic, with very large cycle to cycle variability, with the HT sometimes not igniting at all.

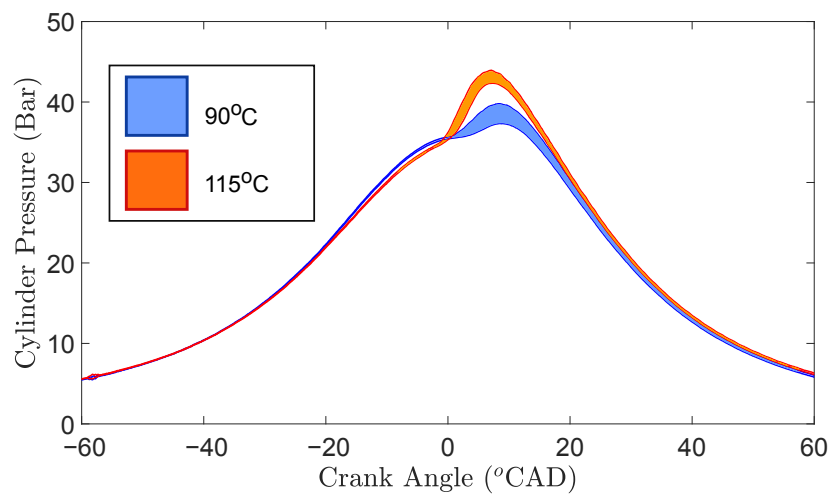

Figure 11. Combustion pressure for $\mathrm{HT}$ at $\mathrm{T}_{\text {inlet }} 90^{\circ} \mathrm{C}$ (blue) and $115^{\circ} \mathrm{C}$ (red). Solid region indicates the range of combustion pressures collected. Plotted as an alternative to plotting all 8 combustion pressures as individual curves.

\subsubsection{Optical Results}

The flame of a PRF of this nature produces little soot so there is little hot incandescent soot to image. A large portion of the flame emission is in the blue region of the spectrum and the camera will not detect some of the emissions from the flame. There is a balance required between minimizing exposure times to avoid image blur and avoid saturation and to ensure adequate amount of light falls on the camera sensor. The exposure time of $49.75 \mu$ s was found to be a good compromise. There were regions in the image where the intensity was approaching the upper limit, but these were highly localized. The images have been pegged to the crank angle of the engine knowing the engine speed and the frame rate employed. The average pixel value ( $\left(\mathrm{Pixal}_{\text {mean }}\right)$ for each frame has been used to represent the flame intensity to examine the ignition timing. Figure 12 shows the mean Pixal $_{\text {mean }}$ for the eight combustion cycles considered, matching those of the pressure results presented; pixel value is in arbitrary units (a.u). The solid region around the line represents the range of Pixal mean values for each combustion cycle. The same trend of later SOC is observed with CHD and HT fuels compared to PRF. Flame intensity increases with increasing $\mathrm{T}_{\text {inlet }}$ while $\mathrm{SOC}$ is advanced. 

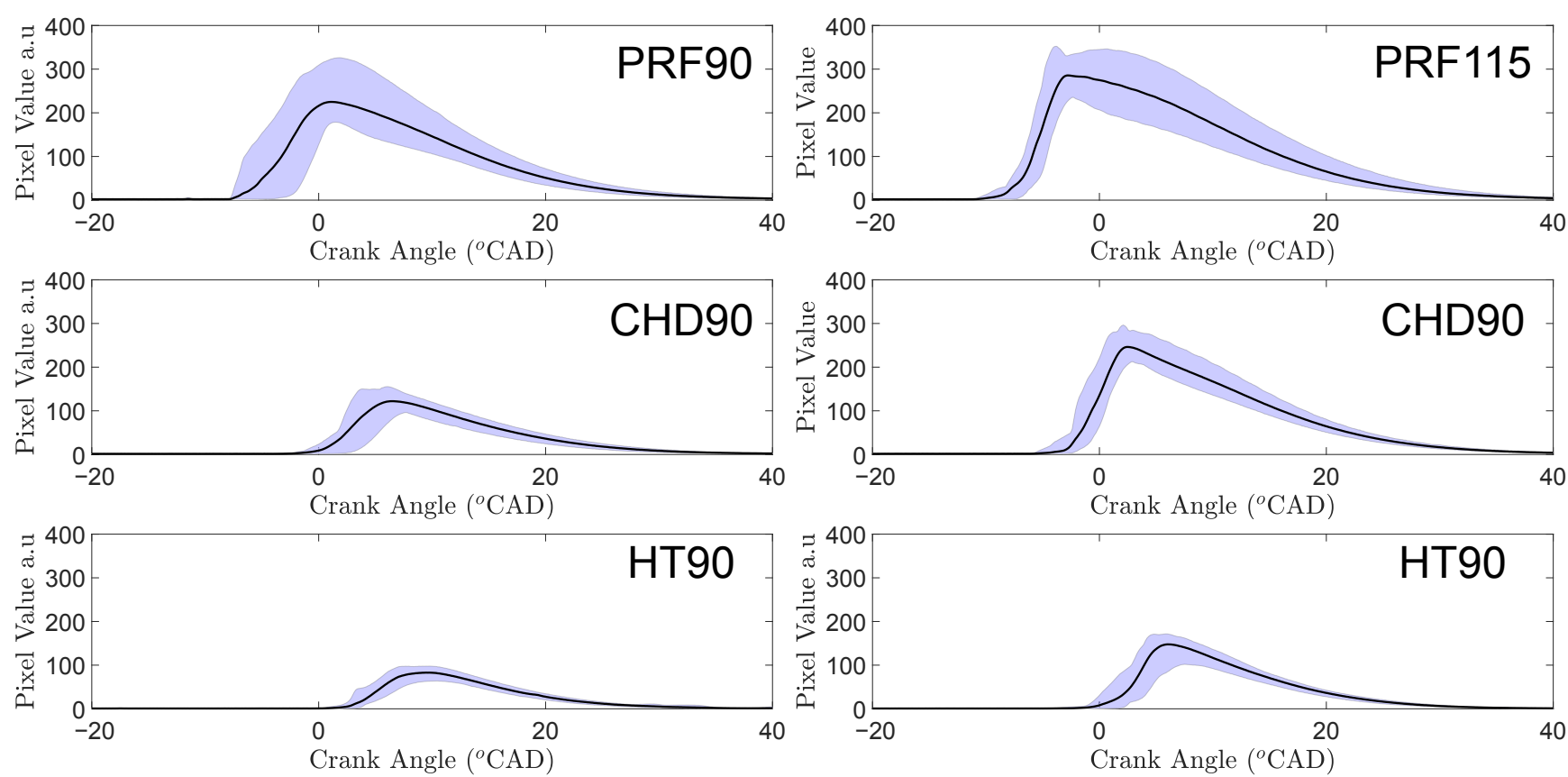

Figure 12. Average pixel intensity (arbitrary units a.u) collected by high speed camera against CAD. Solid black line is the mean value from 8 combustion events, the blue region around the line indicates the range.

The SOC from pressure and from high speed optical are shown in Figure 13. The SOC advances with increasing $\mathrm{T}_{\text {inlet }}$, as would be expected, and is retarded with CHD and HT. For all cases the SOC from pressure and from flame intensity is almost the same apart from the HT, $\mathrm{T}_{\text {inlet }} 90^{\circ} \mathrm{C}$ (HT90) case where the pressure SOC was advanced compared with the intensity SOC ( $\mathrm{SOC}$ from intensity in Figure 13 for this case is negative as plot is CAD BTDC, hence HT90 intensity SOC is after TDC). This may be due to the emissions from the species present during the ignition are not in a wavelength range detectable by the camera, however the enthalpy change was great enough to increase chamber pressure. This effect is not present for the HT $\mathrm{T}_{\text {inlet }} 115^{\circ} \mathrm{C}$ case. This is most likely due to the higher temperature resulting in increased reaction rates, so the ignition period progresses at a higher rate, entering a period where species emissions are detectable earlier; this is supported by the higher HRR for HT115.

Figure 14 shows a sample image captured by the camera for each condition at the $\mathrm{CAD}$ of peak combustion pressure. The image is taken from one combustion cycle only and not constructed from an ensemble average of images for that CAD. The images have been contrasted adjusted for the purpose of presentation here so as to ensure the very low intensity (light blue regions in Figure 14) are visible. This has resulted in 'saturated' yellow regions. Figure 14 aims to demonstrate that the combustion is distributed throughout the chamber and that there is no clear flame front in an effort to validate the assumption that the mixture and subsequent combustion may be considered "well mixed". A more vigorous spectral analysis of the flame emission and application of a high speed intensifier is required to draw any conclusion concerning the impact of CHD and HT on any species formation during ignition but the results presented here clearly demonstrate that the CHD to HT conversation has had a considerable impact on the ignition of the PRF and that it has the potential to be successfully applied as an ignition control strategy. 


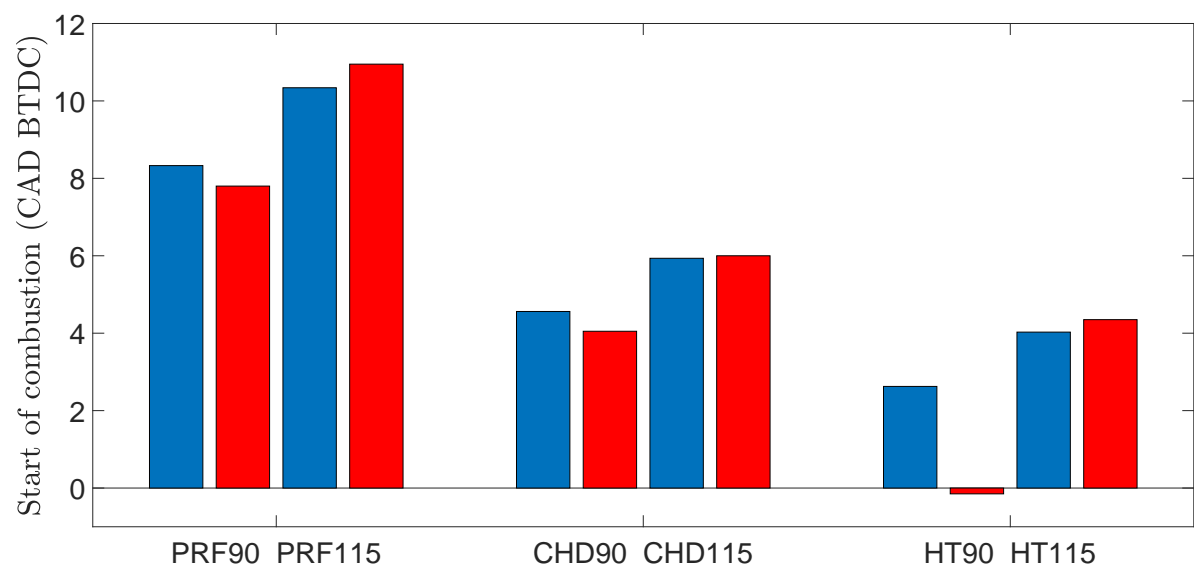

Figure 13. Start of combustion determined from combustion pressure (blue) and optically (red) for the three fuels at the two $\mathrm{T}_{\text {inlet }}$ considered.

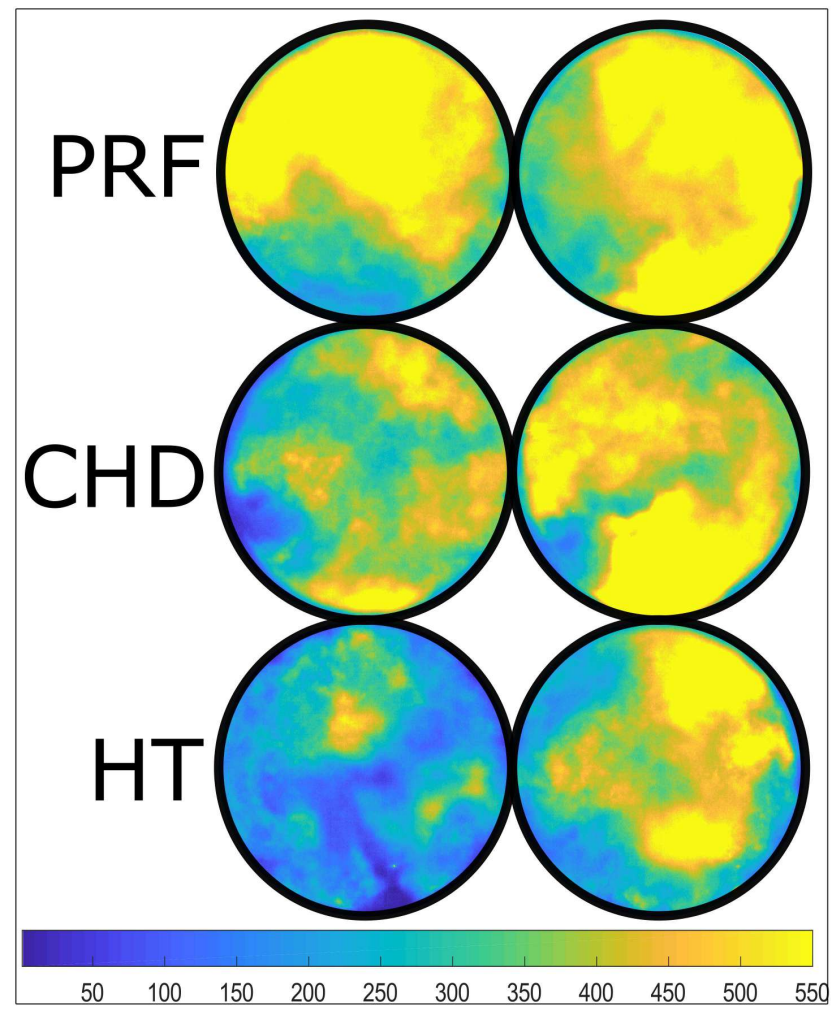

Figure 14. Sample images from a combustion cycle. Images shown are for each fuel, at the two $\mathrm{T}_{\text {inlet }}$ considered $\left(\mathrm{T}_{\text {inlet }} 90^{\circ} \mathrm{C}\right.$ (left), $\mathrm{T}_{\text {inlet }} 115^{\circ} \mathrm{C}$ (right)). Contrast adjusted so all flame is visible (very low intensity flame shown as light blue). The images are taken from one cycle at the CAD where peak pressure for that condition was achieved.

\section{Summary and Conclusions}

Solutions of iso-octane or $n$-heptane with $5 \%$ cyclohexadiene (CHD) were irradiated with UV light for different times in two different reactors: a Pen-Ray reactor, for small $20 \mathrm{~mL}$ samples; and an immersion well reactor, for larger $150 \mathrm{~mL}$ or $400 \mathrm{~mL}$ samples. The CHD underwent a ring opening photo-reaction to convert to hexatriene (HT). The final concentrations of HT were determined using gas chromatography coupled with mass spectrometry (GCMS).

Overall, HT yields were lower than those reported in the literature. The Pen-Ray experiments served as screening tests and to gain knowledge about the reactants and 
reaction conditions. The maximum HT yield was obtained after 120 min in iso-octane; however, the yield in n-hepatne was very similar.

In the immersion well reactor experiments, the maximum irradiation time of $180 \mathrm{~min}$ was applied in order to gain knowledge about the peak conversion experiments, with longer irradiation times needed. The immersion well reactor experiments gave slightly lower HT product yield compared to the Pen-Ray, although the yield is sufficient to achieve the $1 \%$ target after $120 \mathrm{~min}$ of irradiation time. A 1\% HT yield can be produced after $120 \mathrm{~min}$ of irradiation in an iso-octane and CHD solution, hence it was determined that at least $5 \%$ CHD and 120 min of irradiation time should be used to produce the sample to be used in engine testing experiments. Peak HT yield was achieved after $180 \mathrm{~min}$ in the n-heptane solution. Although it was confirmed that the product was stable for a period of a week with moderate $(10 \%)$ degradation, it was recommended to use the finished 'smart' fuel for engine testing directly after production.

For engine testing, a primary reference fuel (PRF) of $90 \%$ iso-octane and $10 \%$ n-heptane was used as a baseline. An engine test solution (ET) of $85 \%$ iso-octane, $10 \% \mathrm{n}$-heptane and $5 \% \mathrm{CHD}$ was irradiated for $240 \mathrm{~min}$ in the immersion well reactor, resulting in $23.4 \% \mathrm{CHD}$ to HT conversion, containing approximately $1.72 \%$ hexatriene.

Engine tests were conducted in a optically accessible compression ignition chamber (OACIC) in the cylinder head of a single cylinder engine. The engine was operated in HCCI mode utilizing an early injection (60 CAD BTDC), $\mathrm{T}_{\text {inlet }} 90$ and $115^{\circ} \mathrm{C}$ and $\mathrm{P}_{\text {inlet }}$ 1.36 bar. A primary reference fuel (PRF) of $90 \%$ iso-octane and $10 \%$ n-heptane was used as a baseline, then a PRF with $85 \%$ iso-octane, 10\% n-heptane and 5\% CHD was used, followed by the ET solution. Combustion pressures for eight cycles have been examined and used to determine the heat release rate. High speed imaging using a camera at 20,000 fps was used to measure flame luminosity, no intensification has been used so much of the very early emission is not captured. Mean pixel value has been used to examine flame intensity. Observations are summarized as;

- Increasing $\mathrm{T}_{\text {inlet }}$ advanced the start of combustion (SOC).

- $\quad$ CHD addition retarded the SOC and reduced heat release rate compared with the PRF.

- The HT containing PRF had a retarded SOC and heat release rate was significantly reduced compared with both PRF and CHD fuels.

- CHD and HT reduced flame intensity as observed by the camera.

This study has successfully validated the use of a photo-chemical 'smart' fuel to significantly change the ignition quality a fuel in HCCI mode combustion and demonstrated the concept of an on-board 'smart fuel' applications for ICE. Further investigations will address the current observations of wax precipitate forming during the CHD addition to the PRF and the optimization of the CHD to HT conversion efficiency during irradiation in order to obtain a practically feasible irradiation timing for on-board applications.

Author Contributions: Conceptualization, A.S. and I.S.; methodology, J.S. and D.E.; formal analysis, J.S. and D.E.; investigation, J.S. and D.E.; writing-original draft preparation, J.S. and D.E.; supervision, T.L. All authors have read and agreed to the published version of the manuscript.

Funding: The authors acknowledge the financial support by the Research Council of Norway through the project SmartFuels, RCN project number-255144.

Data Availability Statement: Not applicable.

Conflicts of Interest: The authors declare no conflict of interest.

\section{Abbreviations}

The following abbreviations are used in this manuscript:

$$
\begin{array}{ll}
\text { CAD } & \text { crank angle degrees } \\
\text { CHD } & 1,3 \text {-cyclohexadiene } \\
\text { CI } & \text { compression ignition }
\end{array}
$$




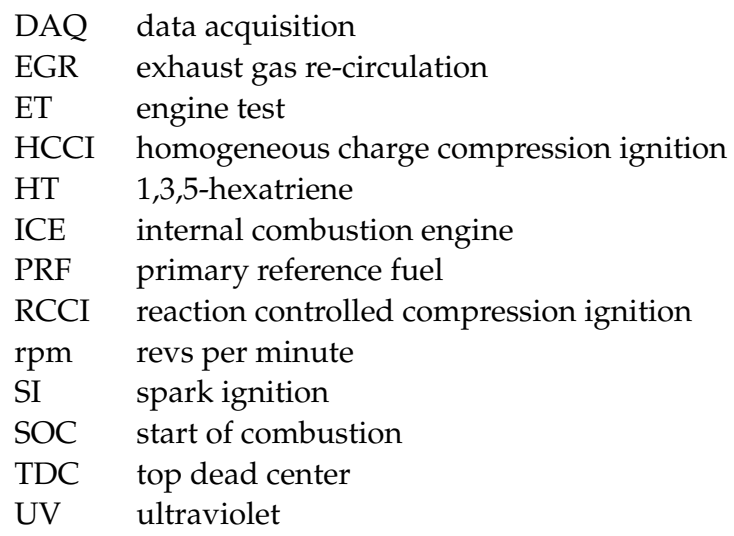

\section{References}

1. Reitz, R.D. Directions in internal combustion engine research. Combust. Flame 2013, 160, 1-8. [CrossRef]

2. Dec, J.E. Advanced compression-ignition engines, understanding the in-cylinder processes. Proc. Combust. Inst. 2009, 32, 2727-2742. [CrossRef]

3. Musculus, M.P.; Miles, P.C.; Pickett, L.M. Conceptual models for partially premixed low-temperature diesel combustion Prog. Energy Combust. Sci. 2013, 39, 246-283. [CrossRef]

4. Reitz, R.D.; Duraisamy, G. Review of high efficiency and clean reactivity controlled compression ignition (RCCI) combustion in internal combustion engines. Prog. Energy Combust. Sci. 2015, 46, 12-71. [CrossRef]

5. Lu, X.; Han, D.; Huang, Z. Fuel design and management for the control of advanced compression-ignition combustion modes Prog. Energy Combust. Sci. 2011, 37, 741-783. [CrossRef]

6. Yao, M.; Zheng, Z.; Liu, H. Progress and recent trends in homogeneous charge compression ignition (HCCI) engines. Prog. Energy Combust. Sci. 2009, 35, 398-437. [CrossRef]

7. Splitter, D.A.; Reitz, R.D. Fuel reactivity effects on the efficiency and operational window of dual-fuel compression ignition engines. Fuel 2014, 118, 163-175. [CrossRef]

8. Kokjohn, S.L.; Musculus, M.P.; Reitz, R.D. Evaluating temperature and fuel stratification for heat-release rate control in a reactivity-controlled compression-ignition engine using optical diagnostics and chemical kinetics modeling. Combust. Flame 2015, 162, 2729-2742. [CrossRef]

9. Tong, L.; Wang, H.; Zheng, Z.; Reitz, R.; Yao, M. Experimental study of RCCI combustion and load extension in a compression ignition engine fueled with gasoline and PODE. Fuel 2016, 181, 878-886. [CrossRef]

10. Eyal, A.; Tartakovsky, L. Second-law analysis of the reforming-controlled compression ignition. Appl. Energy 2020, $263,114622$. [CrossRef]

11. Starck, L.; Lecointe, B.; Forti, L.; Jeuland, N. Impact of fuel characteristics on HCCI combustion: Performances and emissions Fuel 2010, 89, 3069-3077. [CrossRef]

12. Yao, M.; Chen, Z.; Zheng, Z.; Zhang, B.; Xing, Y. Study on the controlling strategies of homogeneous charge compression ignition combustion with fuel of dimethyl ether and methanol. Fuel 2006, 85, 2046-2056. [CrossRef]

13. Schonborn, A.; Hellier, P.; Aliev, A.E.; Ladommatos, N. Ignition control of homogeneous-charge compression ignition (HCCI) combustion through adaptation of the fuel molecular structure by reaction with ozone. Fuel 2010, 89, 3178-3184. [CrossRef]

14. Goldsmith, J.E.M. Photochemical effects in two-photon-excited fluorescence detection of atomic oxygen in flames. Appl. Opt. 1987, 26, 3566-3572. [CrossRef] [PubMed]

15. Bezgin, L.V.; Kopchenov, V.I.; Kuleshov, P.S.; Titova, N.S.; Starik, A.M. Numerical study of combustion initiation in a supersonic flow of H2 and air mixture by resonance laser radiation. J. Phys. D Appl. Phys. 2012, 45, 085401. [CrossRef]

16. Schonborn, A. A 'smart' fuel of photochemically-controlled reactivity. Fuel 2016, 165, 389-396. [CrossRef]

17. Minnaard, N.G.; Havinga, E. Some aspects of the solution photochemistry of 1,3-cyclohexadiene, (Z)- and (E)-1,3,5-hexatriene. Recl. Trav. Chim. Pays Bas 1973, 92, 1315-1320. [CrossRef]

18. Bjørgen, K.O.P.; Emberson, D.R.; Lovas, T. Diffuse Back-Illuminated Extinction Imaging of Soot: Effects of Beam Steering and Flame Luminosity. In Proceedings of the International Powertrains, Fuels \& Lubricants Meeting, San Antonio, TX, USA, 22-24 January 2019; SAE International: Warrendale, PA, USA, 2019.

19. Schönborn, A. Autoignition Control of Fuel and Air Mixtures Using Photochemical Isomerization. Energy Fuels 2018, 32, 12930-12935. [CrossRef]

20. Sirjean, B.; Buda, F.; Hakka, H.; Glaude, P.; Fournet, R.; Warth, V.; Battin-Leclerc, F.; Ruiz-Lopez, M. The autoignition of cyclopentane and cyclohexane in a shock tube. Proc. Combust. Inst. 2007, 31, 277-284. [CrossRef] 